\title{
Remarkable facts about the history of the Brazilian Society of Tropical Medicine
}

\author{
Naftale Katz ${ }^{[1],[2]}$
}

[1]. Professor Emérito, Laboratório de Esquistossomose, Centro de Pesquisas René Rachou, Fundação Oswaldo Cruz, Belo Horizonte, MG. [2]. Presidente da Sociedade Brasileira de Medicina Tropical (1985-1986).

\section{Dear Editor,}

The Brazilian Society of Tropical Medicine (BSTM) was established in the 1960s in an effort to bring together numerous academic members, professors and researchers from different universities and faculties throughout the country as a counterpoint to the Brazilian Society of Hygiene (Sociedade Brasileira de Higiene- SBH). In those days, the SBH experienced a marked reduction in activity that continued until it ceased to exist. It must be remembered that the $\mathrm{SBH}$, which was established in the 1920s, was very important and was the leader in the control of parasitic endemic diseases through its various programs and projects. In the beginning, the members of the SBH were mostly health workers but also included researchers and professors. Carlos Chagas was one of the many active and important presidents that belonged to this society.

Over the decades, there was a separation in Brazil between the activities and claims of the so-called sanitarians, who participated in control services, and the activities of researchers and university professors.

The BSTM was very important in re-founding the Brazilian Society of Parasitology (Sociedade Brasileira de Parasitologia - SBP), which was originally founded in 1965 . Dr. Wladimir Lobato Paraense was its first president and was followed by Professor Amilcar Vianna Martins. With Martins' forfeiture and mandatory retirement in 1969 due to the infamous Institutional Act $\mathrm{n}^{\circ}$ 5, produced by the military dictatorship that assumed control of the country in 1964, the Society ceased to function. However, it was re-established in 1975 under the leadership of Professor Rubens Campos from the State of São Paulo.

For 10 years, the Society held combined annual meetings with the BSTM, from which it received all of its necessary support and funding. It is valuable to note that expert groups were created in the BSTM, sometimes formally or informally. These groups were extremely important because they could ensure that ineffective drugs and vaccines for the treatment of Chagas disease were not offered for sale. Similarly, glucosamine

\footnotetext{
Address to: Dr. Naftale Katz. Laboratório de Esquistossomose/CPqRR/ FIOCRUZ. Av. Augusto de Lima 1715, 30190-002 Belo Horizonte, MG, Brasil. Phone: 5531 3349-7700

e-mail: nkatz@cpqrr.fiocruz.br

Received 10 January 2014

Accepted 24 February 2014
}

and other inactive drugs were not approved for the treatment of schistosomiasis. In addition, the Society also participated in the design of policies in the area of Public Health by the Ministry of Health and/or state health departments.

However, in the 1980s, due to disagreements between two members of the BSTM disputing the Chair of Tropical Medicine at the Medical Faculty of São Paulo University, the Brazilian Society of Infectious Diseases (Sociedade Brasileira de Doenças Infecciosas - SBDI) was founded. Within a few years, the SBDI began to have a strong influence in this area. In addition, the creation of the SBDI satisfied a significant number of medical professionals in the infectious disease field who did not feel at ease in the BSTM. The two Societies contributed a great deal to the development of knowledge in their respective areas, and although there have been several attempts to merge the two organizations, they remain distinct to this day. Currently, the two Societies fulfill their distinct roles, coexist in an environment of collaboration and mutual respect and are a benefit to Brazil.

In the history of the BSTM (in particular, in the development and growth of this Society), the importance of the withdrawal of the general secretariat's fixed headquarters in Rio de Janeiro should also be stressed. As a result, the general secretariat became mobile, that is, located next to each president, which allows decision-making by the board. Additionally, the position is rotated every two years among the different states of the Federation. This reorganization reduced the concentration of power in the hands of the general secretary, which occurred in the beginning of the BSTM's activities.

The importance of the assemblies held in all of the annual congresses must be emphasized. Examples of beneficial outcomes of these assemblies include the decision that guided the ethical relationship of the Society with the pharmaceutical industries and the development of an excellent journal, among others.

In this summary, we have raised some issues that may become important topics for further research; we have explained why our Society was founded; and we have described its striking productivity and participation in the creation, development and application of knowledge in the area of tropical medicine for the benefit of the Brazilian population.

\section{CONFLICT OF INTEREST}

The author declare that there is no conflict of interest. 